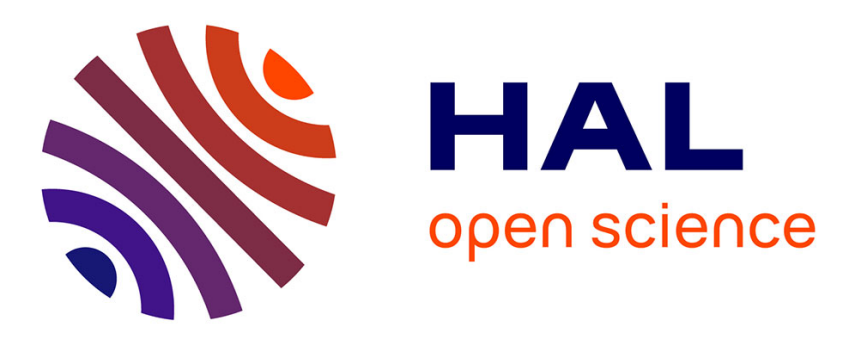

\title{
Modelling of autogenous healing in Ultra High Performance Concrete
}

\author{
Benoit Hilloulin, F. Grondin, M. Matallah, A. Loukili
}

\section{To cite this version:}

Benoit Hilloulin, F. Grondin, M. Matallah, A. Loukili. Modelling of autogenous healing in Ultra High Performance Concrete. Cement and Concrete Research, 2014, 61-62, pp.64-70. 10.1016/j.cemconres.2014.04.003 . hal-03562242

\section{HAL Id: hal-03562242 \\ https://hal.science/hal-03562242}

Submitted on 8 Feb 2022

HAL is a multi-disciplinary open access archive for the deposit and dissemination of scientific research documents, whether they are published or not. The documents may come from teaching and research institutions in France or abroad, or from public or private research centers.
L'archive ouverte pluridisciplinaire HAL, est destinée au dépôt et à la diffusion de documents scientifiques de niveau recherche, publiés ou non, émanant des établissements d'enseignement et de recherche français ou étrangers, des laboratoires publics ou privés. 


\section{Modelling of autogenous healing in Ultra High Performance Concrete}

\section{$9 \quad$ Highlights}

10 - A hydro-chemo-mechanical model of autogenous healing of concrete is developed.

11 - Mechanical properties of the healed crack are assessed.

12 - Quantification of the healing product mechanical properties is proposed.

\section{Abstract}

15 The restoration of ultra high performance concrete (UHPC) specimens due to the self16 healing phenomenon was investigated in this paper. A hydro-chemo-mechanical model 17 based on micro-mechanical observations was established. The aim was to evaluate the mechanical properties of the new healing products in order to describe the partial recovery of the mechanical properties of healed concrete. An analysis of the influence of some physical parameters provided first explanations about the self-healing phenomenon. It

21 was shown that the mechanical properties of $\mathrm{CSH}$ in the healed crack are lower than the ones of the virgin material.

24 Keywords: Self-healing (C), Modelling (E), Mechanical properties (C), Calcium25 Silicate-Hydrate (C-S-H) (B), Characterization (B) 


\section{Introduction}

27 Although occurrence of cracks in concrete structures is taken into consideration during design, cracks generate important inspection and repairing costs. Some of them can seriously affect the durability and the stability of the structures. Thus, self-healing concrete could be a mean to make important savings decreasing direct and indirect costs caused by repairing works $[1,2]$. It has been observed by many researchers that cracks in concrete can heal naturally, without any particular additive, under favourable conditions [3-11]. This phenomenon called 'autogenous' healing is the consequence of two main reactions [12]: further hydration of unhydrated particles upon water ingress into the crack, especially for concrete with an important amount of unhydrated cement particles $[13,14]$ and precipitation of calcium carbonate due to the reaction between calcium contained in the cementitious matrix with carbon dioxide dissolved in the water filling the crack [15]. Some studies have reported the predominance of the precipitation phenomenon in common concrete with a water-to-cement $(\mathrm{y} / \mathrm{c})$ ratio around 0.5 leading to the filling of cracks with an initial width up to around $200 \mu \mathrm{m}$ [10]. Autogenous healing by further hydration has been studied by several researchers because of expected mechanical regains due to the creation of new calcium silicate hydrates (C-S-H). A global recovery of stiffness can be achieved by further hydration $[16,18]$. But, regains in compressive or flexural strengths have been found to be limited $[8,10,14]$ because of relatively poor mechanical properties of the healing product.

Only few models were developed to describe self-healing of concrete. Some models were proposed to determine the amount of unhydrated cement particles in concrete specimens considering $\mathrm{w} / \mathrm{c}$ ratio and cement fineness which underlies the self-healing potential $[17$, $19,20]$, or to calculate the amount of healing product due to further hydration considering 
51 further hydration by water release by a capsule in a crack using water transport theory,

52 ion diffusion theory and thermodynamics theory. However, these models do not provide any information about the mechanical effects of self-healing.

In this study, a hydro-chemo-mechanical model was developed to simulate autogenous healing by further hydration with the aim to explain the mechanical regains after healing and provide information about the self-healing product. Experimentally, Granger et al. [14] used ultra high performance cementitious material (UHPC) with a w/c ratio close to 0.2 to study the self-healing of small cracks with initials widths of 10,20 and $30 \mu \mathrm{m}$. Mechanical properties of healed and uncracked specimens were compared at different 60 stages (1 week, 3 weeks, 10 weeks, 20 weeks and 40 weeks). The hydro-chemo61 mechanical model has been implemented in the finite element code Cast3M [25] to calculate the self-healing potential of a damaged concrete beam after cracking using three-point-bending test. Damage has been calculated by a modified microplane model $[26,27]$. Ingress of water has been simulated by the Fick's law and water interaction with the unhydrated cement particles led to their hydration considering a hydration model [28, 29]. The recovery of mechanical properties of the cracked concrete beam was obtained by decreasing the local damage value due to the filling of empty spaces by new hydrates. In the first part of this article, the relationships underlying the model will be explained into details and the model algorithm will be presented. Furthermore, the numerical results will be compared with experimental measurements and an analysis of the self-healing phenomenon will be suggested.

\section{Description of the self-healing model}

\subsection{Problem formulation}


76 The resolution of the global problem consists on the resolution of a first mechanical

77 problem (P1) corresponding to the initial creation of a single crack, followed by a coupled

78 hydro-chemical problem corresponding to the healing process (P2), and is concluded by

79 a second resolution of a mechanical problem (P3) due to the mechanical changes

80 implicated by the healing process.

81 We consider a volume $\mathrm{V}$ representing the specimen. The specimen is submitted to

82 successive loads of different types: displacements $\bar{U}_{i}$ are applied on the boundaries $\Gamma_{i}^{u}$,

83 the force $\bar{F}$ is applied on the boundary $\Gamma^{\sigma}$, the velocity (or pressure, or concentration) is

84 applied on the boundary $\Gamma^{C}$. The problems P1 and P3 are similar and lead to the

85 calculation of the local displacement fields $(\bar{u}(\bar{y}))$, strain fields $(\bar{\varepsilon}(\bar{y}))$ and stress fields

$86(\bar{\sigma}(\bar{y}))$ as follow (where volume forces are negligible):

$87 \overline{\operatorname{div} \sigma}=\overline{0}$

$\bar{y} \in V$

88

$\bar{\sigma}(\bar{y})=(1-d(\bar{y})) \widetilde{C}^{t}(\bar{y}):\left(\bar{\varepsilon}(\bar{y})-\varepsilon^{p}(\bar{y})\right)$

$\bar{y} \in V$

$89 \quad \bar{\varepsilon}(\bar{y})=\frac{1}{2}\left(\overline{\bar{\nabla}} \bar{u}(\bar{y})+{ }^{t} \overline{\bar{\nabla}} \bar{u}(\bar{y})\right)$

$\bar{y} \in V$

$90 \quad \bar{u}(\bar{y})=\bar{U}_{i}$

$\bar{y} \in \Gamma_{i}^{u}$

$91 \bar{F}=\bar{\sigma}(\bar{y}) \cdot \bar{n}$

$$
\bar{y} \in \Gamma^{\sigma}
$$

92 where $\widetilde{C}^{t}(\bar{y})$ represents the local stiffness tensor of $4^{\text {th }}$ order depending on the time $(\mathrm{t}=$

930 corresponds to the problem $\mathrm{P} 1$, and $\mathrm{t}>0$ corresponds to the problem $\mathrm{P} 3$ ) and $\frac{=p}{\varepsilon}$ the 
94 plastic strain (computed using a loading function by the normality rule). The evolution of

95 the damage is given by [27]:

$96 \quad d=1-\frac{\varepsilon_{d 0}}{\varepsilon_{e q}} \exp \left[B_{t}\left(\varepsilon_{d 0}-\varepsilon_{e q}\right)\right]$

97 where $B_{t}=\frac{f_{t}}{\frac{G_{f}}{h}-\frac{f_{t} \cdot \mathcal{E}_{d_{0}}}{2}}$ represents a damage parameter to control the slope of the

98 strain softening constitutive relation in function of the width $h$ of the finite element and

99 the fracture energy [36], $\varepsilon_{d 0}=\frac{f_{t}}{E}$ the strain threshold and $\varepsilon_{e q}$ the equivalent strain

$100 \quad\left(\varepsilon_{e q}=\sqrt{\frac{=e}{\varepsilon}: e} \quad\right.$ where $\varepsilon$ is the elastic strain $)$.

101 To model the autogenous self-healing (problem P2), external humidity conditions are

102 considered by the contact with water on the boundary of the beam (initial concentration

103 of water of 1 outside the beam, 0.2 inside the beam). The ingress of water, with a speed

$104 \mathrm{U}$, through the damaged material was simulated by using the Fick's law:

$105 \quad \frac{\partial U}{\partial T}=D(d) \frac{\partial^{2} U}{\partial X^{2}}$

106 where $D(d)$ represents the diffusion coefficient depending on damage [30, 31]. The

107 evolution of the diffusivity coefficient is calibrated to follow the evolution of the

108 permeability coefficient with damage (eq 8) [31, 32]. For small damage values, it

109 corresponds to an exponential law and for damage values close to 1, it fits the Poiseuille's

110 law. The evolution of the diffusivity coefficient $\mathrm{D}(\mathrm{d})$ is presented in Figure 1.

$111 \log (k)=(1-d) \log \left(k_{p}\right)+d \log \left(k_{d}\right)$

112 Where $k_{p}=u^{2} / 12$ is the permeability for damage close to 1 ( $\mathrm{u}$ is the crack opening) and

$113 k_{d}=k_{0} \exp \left((\alpha D)^{\beta}\right)$ is the permeability for small damage values between 0 and 0.15 (k0 
114 is the initial permeability, $\alpha$ and $\beta$ two constants ranging respectively from 9.4 to 12.3

115 and 1.4 to 1.6$)[30]$.

116

117 The local quantity of water inside the beam is then used to activate the hydration process

118 which determines the volume of each component in the microstructure according to

119 Arrhenius' equation [28, 29]:

$120 \quad \tau_{i} \frac{d \xi_{i}}{d t}=\sim \sim_{-\backslash \supset,}$

121 where $\widetilde{A}$ and $\tau$ represent the normalized affinity and the characteristic time, respectively,

$122 \xi_{i}$ the hydration coefficient of the clinker i.

123 The hydration process leads to the dissolution of clinkers and to the formation of hydrates

124 with a volume defined by:

$V_{k}^{P}(t)=\sum_{l}^{n}\left(V_{i}^{0} \frac{n_{k}^{P} M_{k}}{n_{l}^{R} M_{l}} \frac{\rho_{C}}{\rho_{k}}\right) \xi_{l}(t) \quad k=1, m$

126 where $V_{i}^{0}$ represents the residual clinkers in concrete, $V_{k}^{p}$ the new formed hydrates, $\mathrm{M}$ the

127 molar mass, $\rho$ the mass density and $\mathrm{n}$ the mole. The index $k$ represents the products

128 (clinkers), $l$ the reactants and $c$ the cement.

129 According to the definition of damage as a void volume in the material, we suppose that

130 when the hydration products are created in the damage area, they fill the empty space and

131 decrease the local damage value:

132

$d_{\text {final }}=d_{\text {initial }}-k \frac{V_{\text {hydrates }}}{V_{\text {total }}}$

134 Where $\mathrm{k}$ is a coefficient to eventually adjust the final damage value after healing due to

135 the healing potential, a value of 1 is considered in this study. Up to now, the contribution 
136 of a given healing product from autogenous healing to the observed regain in mechanical

137 properties is not evident. In the experimental results reported here, almost no calcite was

138 formed, so the coefficient $\mathrm{k}$ should be higher than for other concrete were the healing

139 product is a mix of $\mathrm{CSH}$, portlandite and calcite. One should adjust the coefficient k to

140 the effective amount of CSH product created by further hydration.

141 The decrease of the local damage value leads to a decrease of the quantity of water

142 absorbed into the crack during the following time step due to the decrease of the diffusion

143 coefficient.

144 A condensed flowchart of the model is presented in Figure 2.

\subsection{Modelling system}

147 Finite element analysis were performed on a UHPC notched beam $(50 \mathrm{~cm} \times 10 \mathrm{~cm} \times$

$1485 \mathrm{~cm}$ ) with a notch depth of $2 \mathrm{~cm}$ as used by Granger et al. [14]. The centre part of the

149 beam was discretized with elements of $0.75 \mathrm{~mm} \times 1 \mathrm{~mm}$ size. Three-point-bending tests

150 were simulated on a concrete beam before and after healing to simulate, respectively, the

151 creation of a single crack, and the restoration of the mechanical properties.

152 The numerical simulations have been performed under displacement control with constant displacement step of $5 \times 10^{-7} \mathrm{~m}$ at the top of the beam, considering a vertical displacement of the notch where the load was applied and rolling supports under the beam as illustrated in Figure 3. The crack mouth opening displacement (CMOD) was calculated

156 considering the evolution of the relative displacement of two nodes placed under the

157 beam, at the same position as in the experimental instrument ( $1 \mathrm{~cm}$ of initial opening).

158 For the healing procedure, an initial moisture diffusion coefficient of $10^{-9} \mathrm{~m}^{2} / \mathrm{s}$ was 159 considered for undamaged zones [33]. 
160 In order to describe the hydration process at a mesoscopic scale, an initial uniform volume

161 fraction of clinker of 0.12 was applied. This initial volume fraction corresponds to a

162 volume fraction of anhydrous clinkers of around $50 \%$ in the cement paste. The local

163 volume fraction of clinker was decreased at each time step after the diffusion of water

164 according the pre-set hydration speed. The first hydration speed considered in this study

165 was comparable to a speed of a new concrete mix. The hydration speed was then

166 decreased to investigate its role on the healing kinetics.

167 Different numerical time steps were investigated from 1 second to 6 hours after several 168 days of healing.

\section{Results and discussion}

3.1. Pre-cracking stage and mechanical parameters of the virgin specimen

172 Some constitutive damage parameters (Young's modulus (E), Poisson's ratio (v), tensile

173 and compressive strengths $\left(f_{t}\right.$ and $\left.f_{c}\right)$ ) were measured experimentally and fracture energy

$174\left(\mathrm{G}_{\mathrm{f}}\right)$ was adjusted to perform the three-point-bending simulations on a notched beam, in

175 order to fit the experimental loading curves during the stage of the creation of the crack.

176 The selected parameters for the mechanical model are presented in Table 1. These

177 parameters gave correct initial stiffness and maximal bearing load and also led to a correct

178 agreement concerning the unloading slope and the final CMOD (around $10 \mu \mathrm{m}$ ) as

179 illustrated in Figure 4. The latter are important in scope to fairly compare numerical and 180 experimental reloading results. 
184 Healing is located all along the crack if the evolution of the diffusion coefficient with

185 damage is the one previously presented. Indeed, diffusion through the crack only takes

186 tens of seconds while the hydration process duration is of around some hours. If the speed

187 of hydration is increased (which seems to be a relevant hypothesis because the high water 188 content in the crack [24] and the direct exposure of clinker on the crack surface), damage 189 can decreased faster locally. Then, the healed zone is located at the bottom part of the 190 crack (Figure 5) because the local reduction of the damage slows down the diffusion 191 process. Thus, the healed zone grows slowly to the top of the beam.

192 Experimentally, healing products (mainly C-S-H) are generally observed all along the 193 crack $[14,34]$. The model can reproduce this trend even though it existed risk of the 194 partial filling of the crack due to its small width. However, this first model considering 195 the water diffusion and the hydration of anhydrous clinker is rather sensitive to the input 196 parameters (speed of rehydration and speed of diffusion as illustrated in Figure 5). Due

197 to the dependence of the model on the speed of rehydration, the choice has been made to 198 develop an external procedure to localise the healing product to focus on the mechanical 199 part of the model in order to identify material parameters of the healing product.

\subsubsection{External localisation procedure and two-phase healing model}

201 In order to limit the dependence of the results on the speed on hydration of clinkers, an external procedure (independent of the hydro-chemical procedure) was developed to localise the healed zone considering the initial crack width and study its influence without

204 taking into consideration the diffusion process described earlier. This procedure was

205 developed to easily study the influence of the size of healed zone on the mechanical regains. Considering that it was not possible to input variably distributed mechanical properties in this external procedure (to represent the evolution of the filling fraction for example), mechanical parameters corresponding to the healing product were input in the 
bottom part of the beam, where the water can react directly with the clinker and fill the

210 crack very quickly. For larger cracks, it is possible that the majority of the healing

211 products could be located where the local crack width would be reasonable $(<100-200$

212 microns [10]).

213 Numerical calculation of the initial crack width was performed according to OUVFISS

214 procedure implemented in Cast3M [35]. Figure 6 a) represents the initial numerical crack

215 width. The initial crack width calculated with this procedure is $8.6 \mu \mathrm{m}$. It consists well

216 with the measured CMOD around 10 .

217 A two-phase healing model, illustrated in Figure $6 \mathrm{~b}$ ), was then developed to study the

218 influence of the mechanical parameters of the healing product on the global mechanical

219 behaviour. The bottom part of the crack, corresponding to the zone where the crack width

220 was larger than the width input in the localisation procedure, was modelled with mechanical parameters independent of the parameters of the virgin specimen. This zone (Z1) situated in the bottom part of the crack is supposed to model the C-S-H healing product. Other mechanical parameters were attributed to the upper part of the crack. This zone (Z2) is supposed to model the mechanical properties of all the others entities present in the crack except the C-S-H healing product. Although the model does not take into account the experimental localisation of the healing product all along the crack, it allows representing the gradient of properties existing in the crack.

\subsection{Reloading}

\subsubsection{Influence of the extend of the healed zone}

231 Because the main interest of the hydro-chemical procedure is the localisation of the healed

232 zone, the influence of this localisation on the mechanical properties of the healed 233 specimen was firstly studied. Several reloading with different healed zone sizes and 
234 localisations were simulated assuming the same mechanical properties for the healing

235 product than for the virgin specimen (damage locally reduced to 0 ).

236 When the bottom part of the crack was not healed, the initial slope of the reloading curve

237 in the load vs CMOD graph was smaller than all the experimental results with healing.

238 This could indicate that healing products were formed at the bottom part of the crack even

239 if it was the wider part of the crack. It could be explained by the small maximum aperture

240 of the crack which is comparable to the size of the unhydrated clinker and therefore more

241 likely to be closed by hydration products. The healing localisation may be different for

242 wider cracks with maximum crack width of around $100-300 \mu \mathrm{m}$ because hydration

243 products (C-S-H) cannot fill this gap completely as reported by many experimental

244 studies $[10,15,17]$.

245 On the other hand, healing in the bottom part of the crack is not sufficient to restore the mechanical properties (stiffness and maximum bearing load) even if the healing product

247 has the same mechanical properties as the yirgin specimen. Extend of the healed zone 248 needs to be sufficient. In our model, a height of the healed zone of around one fourth of

249 the crack length (zone where the initial crack width is larger than $7 \mu \mathrm{m}$ ) seems sufficient

250 to restore the initial slope of the load vs. CMOD curve and also the maximum bearing 251 load as illustrated in Figure 7. If the healed zone is too small (zone where the initial crack

252 width is larger than $8-8.5 \mu \mathrm{m}$ which leads to a length of the healed zone of around one 253 eighth to one tenth of the initial crack length) the maximum bearing load and the stiffness 254 cannot consist well with experimental results. In this case, the maximum bearing load 255 increases with the size of the healed zone.

256 Thus, according to the experimental results showing a rather quick regain in stiffness

257 (different than the hysteresis phenomenon) and the numerical calculations, we can assume 
that healing product was, at least, created at the bottom part of the crack and likely recover an extended part of the crack.

\subsubsection{Influence of the mechanical parameters of the healing product}

As exemplified by Figure 7, the experimental bi-linear shape of the reloading curve cannot be reproduced assuming that the healing product has the same mechanical properties than the virgin specimen. Consequently, new mechanical parameters were input to describe the healing product with the two-phase healing model. Thus, it is possible to simulate a healing product with heterogeneous mechanical properties.

According to the two-phase healing model, the bi-linear shape of the experimental reloading curves can mainly be attributed to the difference of the Young's modulus in the two different phases. This difference between the two numerical Young's modulus highlights the heterogeneity of the healed crack: some zones are healed with healing products with very good mechanical properties whereas other zones have very poor mechanical properties because they remain fractured.

273 The maximum bearing load obtained with the simulation is mainly influenced by the

274 fracture energies assigned to both zones. Thus, the small experimental regain in bearing load could be explained by a lower fracture energy in the crack than in the undamaged zone. It leads to an easier recreation and propagation of a crack through the healed zone

277 which has been reported in the experimental observation.

3.3.3. Comparison between numerical and experimental curves and evolution of the healing product properties

281 Numerical simulations were performed adjusting the height of the Zone 1 and the 282 mechanical parameters of both zones in order to fit the experimental curves and obtain 
283 information about the evolution of the healing product over time. The best fitting curves

284 were selected in order to reproduce the original stiffness and the maximum bearing load.

285 These numerical curves were obtained with the parameters detailed in Table 2 and are

286 presented in Figure 8. On all the numerical curves, we can notice an overestimation of

287 the load corresponding to the end of the first initial slope followed by a small drop in

288 load. This is due to the two-phase model where the mechanical properties are not 289 continuous between the two phases. Regarding the material stiffness for the 'No healing'

290 case, numerical and experimental results cannot be compared. Although the mechanical

291 model implemented here reproduce realistic decrease of stiffness and CMOD, it does not

292 reproduce the hysteretic behaviour creating the small recover in stiffness for the cracked

293 specimens due to friction between cracks lips.

294 The size of Z1 was increased with the healing time. This could indicate that, even if the

295 hydration of the first clinker is very quick (first healing products are created within some

296 hours), healing product is still created after some weeks in water. Thus, self-healing by

297 further hydration could follow a 'surface controlled - diffusion controlled process' as

298 described for the precipitation of calcite [15].

299 The mechanical properties inputted the two zones are different than the ones of the virgin

300 specimen. Young's modulus and fracture energy in $\mathrm{Z1}$ are higher than the ones in the

301 virgin specimen. This could be explained by the better mechanical properties of pure C-

302 S-H compared to the concrete. Also, we can notice that the fracture energy of Z1 increases

303 with time [36] which indicates that the healing product has a higher resistance to crack

304 propagation as the healing phenomenon progress. The mechanical properties affected to

$305 \mathrm{Z} 2$ are very low and consist well with the ones of an almost completely damaged zone

306 (Young's modulus close to 0).

307 


\section{Conclusions}

309 In this study, a hydro-chemo-mechanical model for self-healing concrete was developed.

310 The localisation of the healed zone was investigated based on a diffusion-hydration

311 model. Regains in mechanical properties due to healing were assessed with a continuum

312 damage model. Based on the experiments and simulations, conclusions can be drawn as

313 follows:

314 - The mechanical properties of the healed crack are lower than the ones of the virgin

315 material at a mesoscopic scale. This is explained by the partial healing along the

316 crack which leads to a relatively small regain in bearing capacity after healing.

317 - The evolution of the mechanical properties of the healing product (Young's

318 modulus, fracture energy) with time and the increase of its quantity over time

319 explain the evolution of the mechanical properties of the concrete structure.

320 - Partial healing of cracks located around the zone in contact with water can be properties (in autonomous healing solutions for example).

327 Modelling the autogenous healing in concrete is still a great challenge because it relies

328 on the development of coupled models. Further investigations are needed to understand

329 the recovery of mechanical and transport properties. In the future, numerical models may 330 help to assist experimental observations and participate to predict the evolution of 331 concrete structures properties during their service life. 
334 Financial support from the GIS LIRGeC, Région Pays de la Loire (France), for this study 335 is gratefully acknowledged.

336

\section{References}

338 [1] K. van Breugel, Self-healing concepts in civil engineering for sustainable 339 solutions: Potential and constraints, in: Proceedings of the Second International 340 Conference on Self-Healing Materials, 2009.

341 [2] M. de Rooij, K. Van Tittelboom, N. De Belie, E. Schlangen (Eds), Self-Healing

342 Phenomena in Cement-Based Materials, Springer Netherlands, 2013.

343 [3] C. A. Clear, The effect of autogenous healing upon leakage of water through 344 cracks in concrete, Cement and Concrete Association (1985).

345 [4] N. Hearn, C. Morley, Self-sealing property of concrete - experimental evidence, 346 Materials and Structures 30 (7) (1997) 404-411

347 [5] H.-W. Reinhardt, M. Jooss, Permeability and self-healing of cracked concrete as 348 a function of temperature and crack width, Cement and Concrete Research 33 (7) (2003) $349981-985$.

350 [6] M. Li, V. C. Li, Cracking and healing of engineered cementitious composites 351 under chloride environment, ACI Materials Journal 108 (2011) 333-340.

352 [7] S. Jacobsen, J. Marchand, L. Boisvert, Effect of cracking and healing on chloride 353 transport in OPC concrete, Cement and Concrete Research 26 (6) (1996) 869 - 881.

354 [8] S. Jacobsen, E. J. Sellevold, Self healing of high strength concrete after 355 deterioration by freeze/thaw, Cement and Concrete Research 26 (1) (1996) 55 - 62. 
[9] Y. Yang, M. D. Lepech, E.-H. Yang, V. C. Li, Autogenous healing of engineered (2009) $382-390$.

359 [10] K. Van Tittelboom, E. Gruyaert, H. Rahier, N. De Belie, Influence of mix

360 composition on the extent of autogenous crack healing by continued hydration or calcium

361 carbonate formation, Construction and Building Materials 37 (0) (2012) 349 - 359.

362 [11] S. Jacobsen, J. Marchand, H. Hornain, Sem observations of the microstructure of 363 frost deteriorated and self-healed concretes, Cement and Concrete Research 25 (8) (1995) $3641781-1790$.

365 [12] A. Neville, Autogenous healing: A concrete miracle?, Concrete international 24 366 (2002) 76-81.

367 [13] Y. Abdel-Jawad, F. Dehn, Self-healing of self-compacting concrete, in: Fourth 368 International RILEM Symposium on Self-Compacting Concrete (SCC 2005), 2005, pp. $1023-1029$.

[14] S. Granger, A. Loukili, G. Pijaudier-Cabot, G. Chanvillard, Experimental 371 characterization of the self-healing of cracks in an ultra high performance cementitious 372 material: Mechanical tests and acoustic emission analysis, Cement and Concrete 373 Research 37 (4) (2007) $519-527$.

374 [15] C. Edvardsen, Water permeability and autogenous healing of cracks in concrete, 375 ACI Materials Journal 96 (4) (1999) 448-454.

376 [16] P. Pimienta, G. Chanvillard, Durability of UHPFRC specimens kept in various 377 aggressive environments, in: Proceedings of the 10th International Conference On 378 Durability of Building Materials and Components LYON [France] 17-20 April 2005.

379 [17] N. Ter Heide, Crack healing in hydrating concrete, Master's thesis, Delft 380 University of Technology (2005). 
381 [18] N. Ter Heide, E. Schlangen, Self healing of early age cracks in concrete, in:

382 Proceedings of the First international conference on Self Healing Materials, Noordwijk 383 aan Zee, The Netherlands, 18-20 April 2007.

384 [19] H. He, Z.-Q. Guo, P. Stroeven, M. Stroeven, L. Sluys, Self-healing capacity of 385 concrete - computer simulation study of unhydrated cement structure, Image Analysis \& 386 Stereology 26 (2007) 137-143.

387 [20] H. He, Z. Guo, P. Stroeven, M. Stroeven, Numerical assessment of concrete's 388 self-healing potential for promoting durability, International Journal of Modelling, 389 Identification and Control 7 (2009) 142-147.

390 [21] Z. Lv, H. Chen, Modeling of self-healing efficiency for cracks due to unhydrated 391 cement nuclei in hardened cement paste, Procedia Engineering 27 (0) (2012) $281-290$.

392 [22] Z. Lv, H. Chen, Self-healing efficiency of unhydrated cement nuclei for dome393 like crack mode in cementitious materials, Materials and Structures (2013) 1-12.

394 [23] H. Huang, G. Ye, Simulation of self-healing by further hydration in cementitious 395 materials, Cement and Concrete Composites 34 (4) (2012) $460-467$.

396 [24] H. Huang, G. Ye, D. Damidot, Characterization and quantification of self-healing 397 behaviors of microcracks due to further hydration in cement paste, Cement and Concrete $398 \quad$ Research $52(0)(2013) 71-81$.

399 [25] P. Verpaux, T. Charras, A. Millard, Castem 2000: une approche moderne du 400 calcul des structures, Calcul des structures et intelligence artificielle (J.M. Fouet and P. 401 Ladevèze and R. Ohayon) (1988) 261-271.

402 [26] S. Fichant, Endommagement et anisotropie induite du béton de structures. 403 modélisations approchées, Ph.D. thesis, Ecole Normale Supérieure de Cachan (1996). 
404 [27] S. Fichant, C. La Borderie, G. Pijaudier-Cabot, Isotropic and anisotropic 405 descriptions of damage in concrete structures, Mechanics of Cohesive-frictional Materials $4064(4)(1999) 339-359$.

407 [28] O. Bernard, F.-J. Ulm, E. Lemarchand, A multiscale micromechanics-hydration 408 model for the early-age elastic properties of cement-based materials, Cement and 409 Concrete Research 33 (9) (2003) 1293 - 1309.

410 [29] F. Grondin, M. Bouasker, P. Mounanga, A. Khelidj, A. Perronnet, Physico411 chemical deformations of solidifying cementitious systems: multiscale modelling, 412 Materials and Structures 43 (1-2) (2010) 151-165.

413 [30] V. Picandet, A. Khelidj, G. Bastian, Effect of axial compressive damage on gas 414 permeability of ordinary and high-performance concrete, Cement and Concrete Research $41531(11)(2001) 1525-1532$.

416 [31] A. Khelidj, M. Choinska, G. Chatzigeorgiou, G. Pijaudier-Cabot, Coupling 417 between progressive damage, temperature and permeability of concrete : experimental 418 and numerical study., Restoration of Buildings and Monuments 12 (2006) 299-316.

419 [32] M. Choinska, Effets de la température, du chargement mécanique et de leurs 420 intéractions sur la perméabilité du béton de structure, Ph.D. thesis, Ecole Centrale de $421 \quad$ Nantes et Université de Nantes (2006).

422 [33] V. Picandet, G. Bastian, A. Khelidj, Compared imbibitions of ordinary and high 423 performance concrete with null or positive water pressure head, Cement and Concrete 424 Research 38 (6) (2008) $772-782$.

425 [34] S. Granger, Caractérisation expérimentale et modélisation du phénoméne d'auto426 cicatrisation des fissures dans les bétons, Ph.D. thesis, Ecole Centrale de Nantes (2006). 
427 [35] M. Matallah, C. La Borderie, O. Maurel, A practical method to estimate crack 428 openings in concrete structures, International Journal for Numerical and Analytical 429 Methods in Geomechanics 34 (15) (2010) 1615-1633.

430 [36] M. Matallah, M. Farah, F. Grondin, A. Loukili, E. Rozière, Size-independent 431 fracture energy of concrete at very early ages by inverse analysis, Engineering Fracture 432 Mechanics 109 (0) (2013) $1-16$.

433 
434 Table 1. Input mechanical parameters for the virgin specimen

\begin{tabular}{lllll}
\hline $\mathrm{E}^{(*)}$ & $v^{(*)}$ & $\mathrm{f}_{\mathrm{t}}$ & $\mathrm{f}_{\mathrm{c}}{ }^{(*)}$ & $\mathrm{G}_{\mathrm{f}}$ \\
\hline $45 \mathrm{GPa}$ & 0.2 & $7 \mathrm{MPa}$ & $90 \mathrm{MPa}$ & $50 \mathrm{~N} / \mathrm{m}$
\end{tabular}

${ }^{(*)}$ From experimental measurements

436

437

438

439 Table 2. Mechanical parameters input in the two-phase healing model

\begin{tabular}{cccc}
\hline Simulation & Sim 1 week & Sim 10 weeks & Sim 20 weeks \\
\hline Crack width separation & 8 & 7.5 & 7 \\
Zone1/Zone2 $(\mu \mathrm{m})$ & 60 & 60 & 60 \\
$\mathrm{E}_{1}(\mathrm{GPa})$ & 7.2 & 7.2 & 7.2 \\
$\mathrm{~F}_{\mathrm{t} 1}(\mathrm{MPa})$ & 50 & 60 & 80 \\
$\mathrm{G}_{\mathrm{f} 1}(\mathrm{~N} / \mathrm{m})$ & 15 & 15 & 20 \\
$\mathrm{E}_{2}(\mathrm{GPa})$ & 7.2 & 7.2 & 7.2 \\
$\mathrm{~F}_{\mathrm{t} 2}(\mathrm{MPa})$ & 20 & 20 & 25 \\
$\mathrm{G}_{\mathrm{f} 2}(\mathrm{~N} / \mathrm{m})$ & & & \\
\hline
\end{tabular}

440

441

442

443 


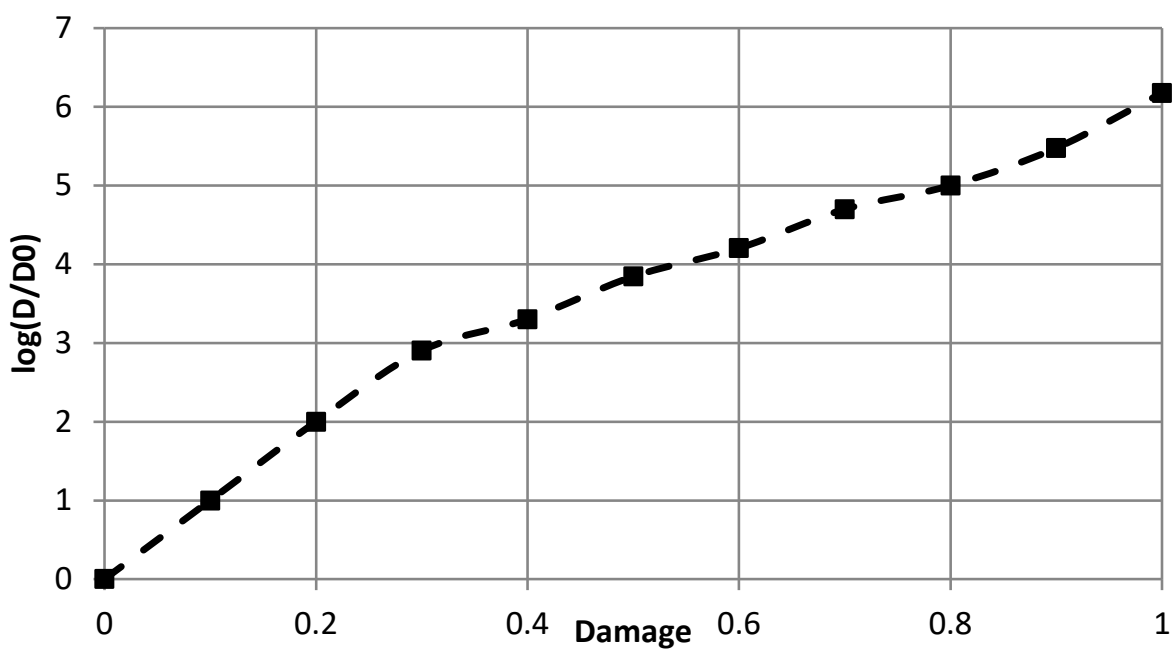

445 Figure 1. Evolution of the diffusivity coefficient with local damage

446

447

448

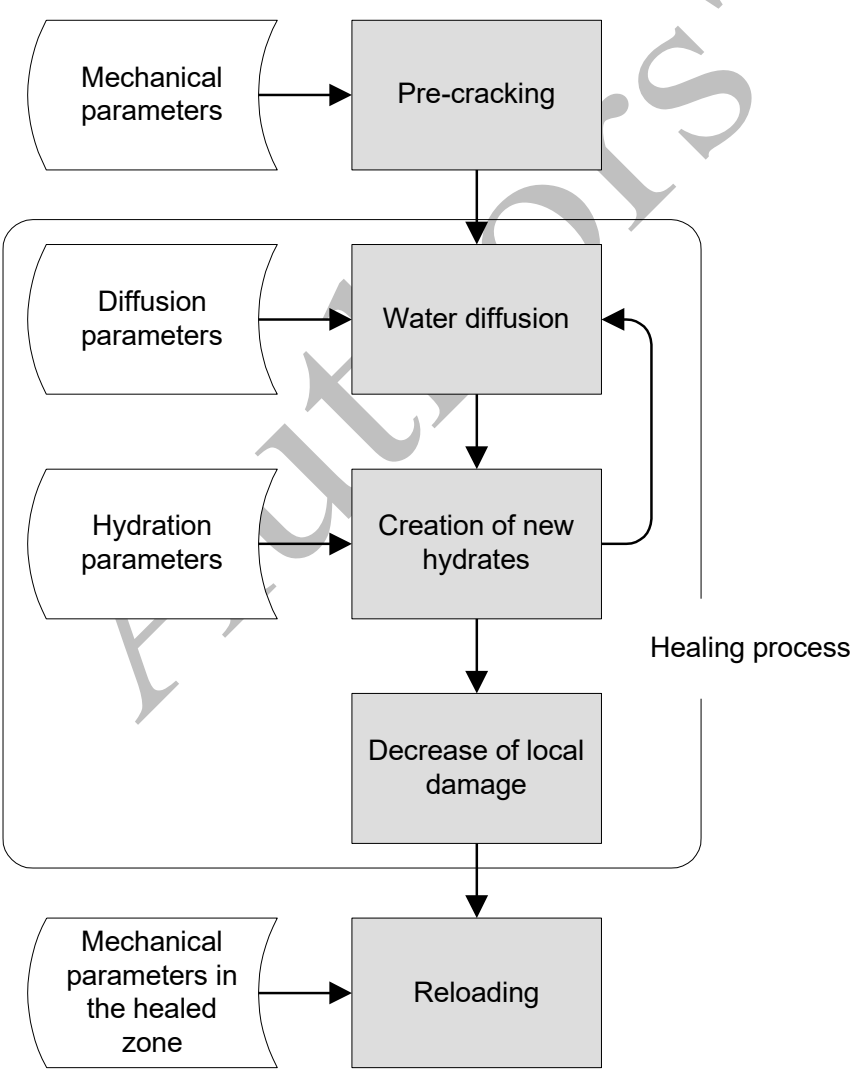

450 Figure 2. Flowchart of the model to study the impact of self-healing on mechanical 


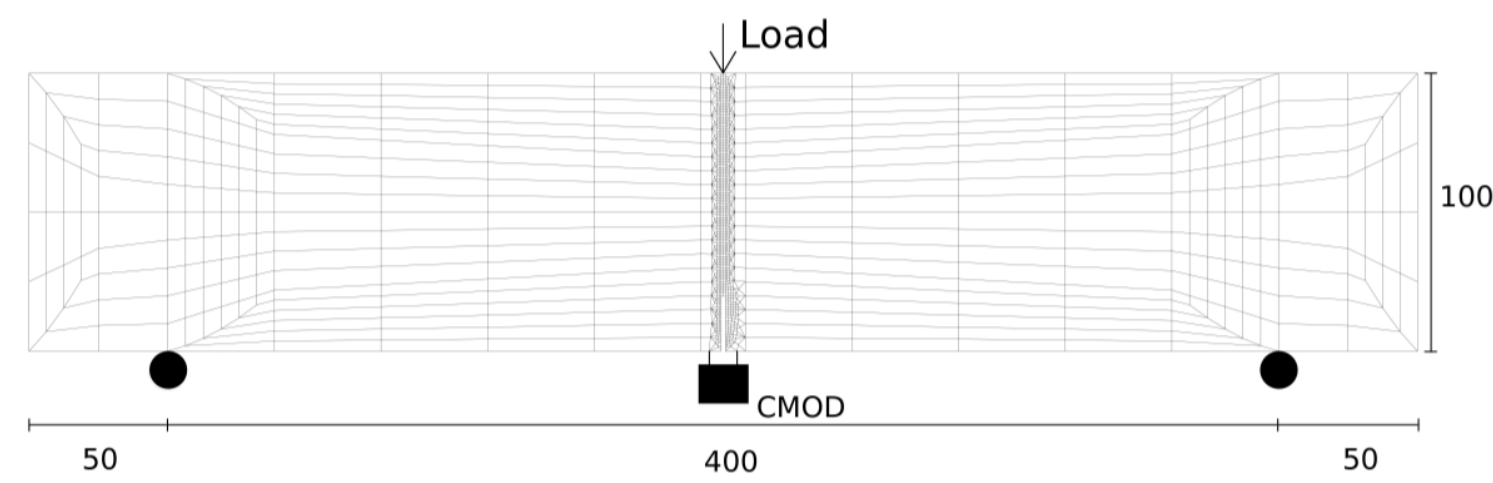

452

453 Figure 3. Notched beam: geometry, mesh, position of numerical CMOD and loading

454

455

456

457

458

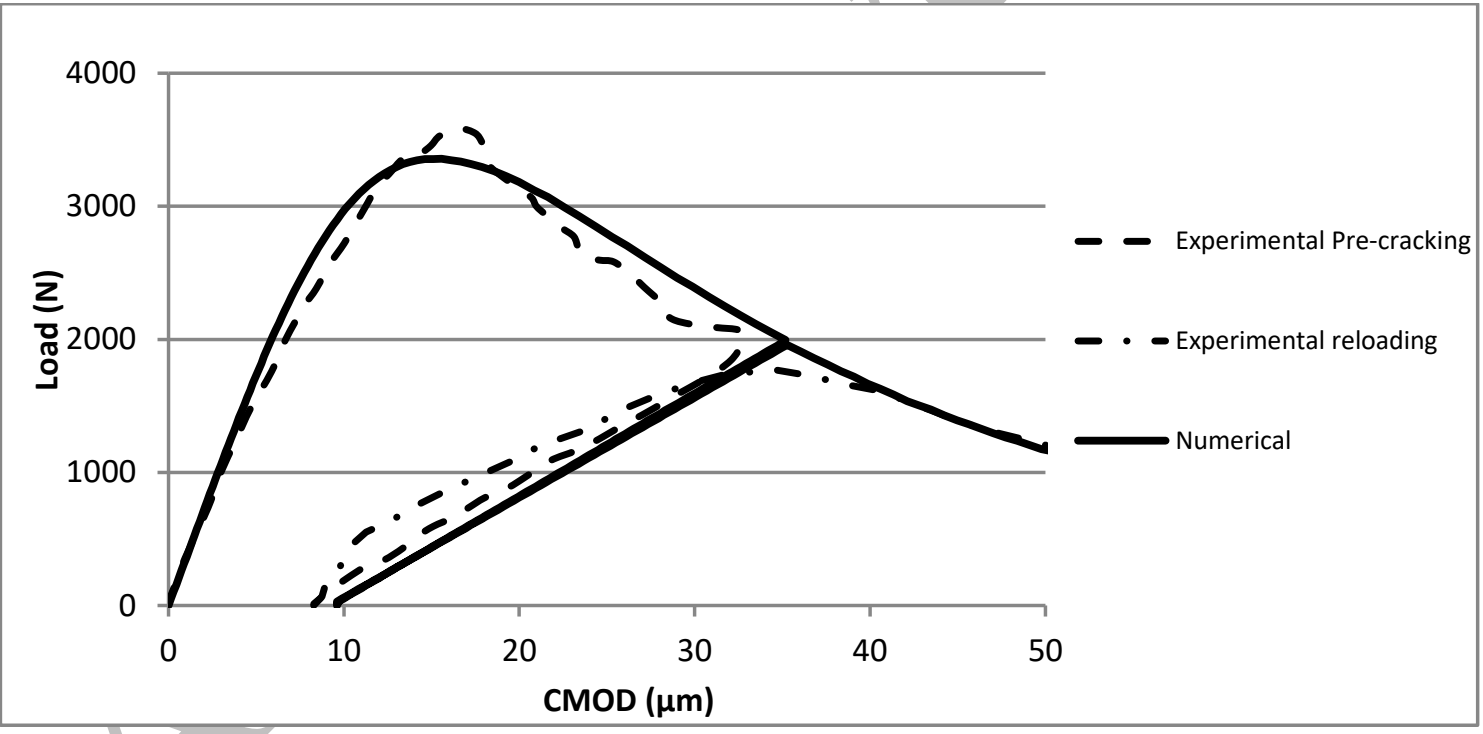

459 Figure 4. Numerical loading curve of the virgin specimen compared to mean experimental data from $[14,34]$.

461

462

463 
VAL - ISO

$>0.00 \mathrm{E}+00$

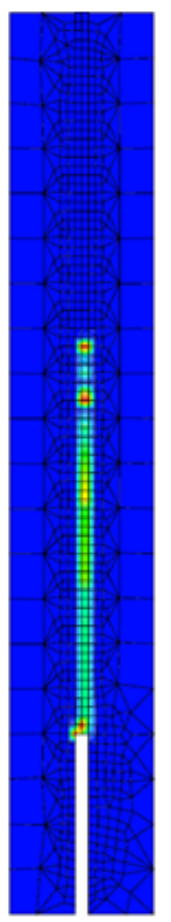

a)

$<2.26 \mathrm{E}-02$

2. 25E-02

2. 14E-02

2. 03E-02

1. $92 \mathrm{E}-02$

1. $82 \mathrm{E}-02$

1. $71 \mathrm{E}-02$

1. $60 \mathrm{E}-02$

1. 49E-02

1. $38 \mathrm{E}-02$

1. $28 \mathrm{E}-02$

1. $17 \mathrm{E}-02$

1. $06 \mathrm{E}-02$

9. 53E-03

8. $45 \mathrm{E}-03$

7. $37 \mathrm{E}-03$

$6.29 \mathrm{E}-03$

$5.21 \mathrm{E}-03$

4. $13 \mathrm{E}-03$

3. $06 \mathrm{E}-03$

1. $98 \mathrm{E}-03$
8. $99 \mathrm{E}-04$

465 Figure 5. Residual damage after 20 days of healing a) with normal diffusion and

466 hydration parameters (residual damage close to 0 all along the crack), b) with increased

467 hydration (crack completely healed at its bottom part)
VAL - ISO

$>0.00 \mathrm{E}+00$

$<4.96 \mathrm{E}-01$

0.49

0.47

0.44

0.42

0.40

0.37

0.35

0.33

0.30

0.28

0.26

0.23

0.21

0.18

0.16

0.14

0.11

9. $05 \mathrm{E}-02$

6. $69 \mathrm{E}-02$

4. 33E-02

1. $97 \mathrm{E}-02$ b)
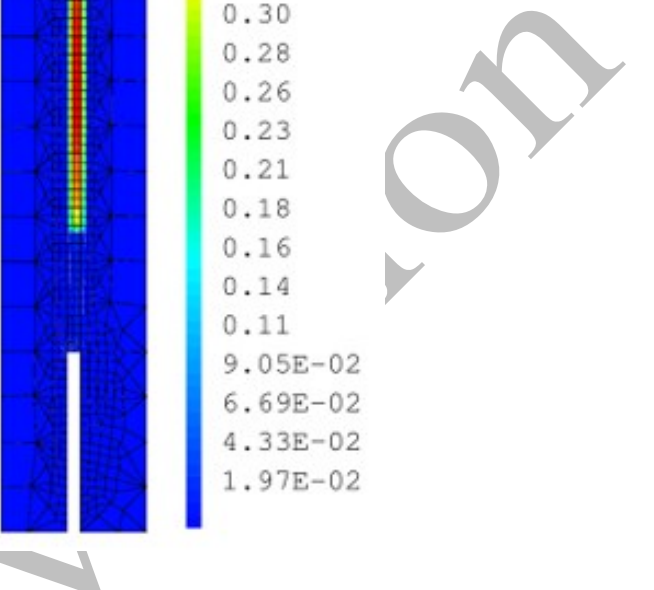


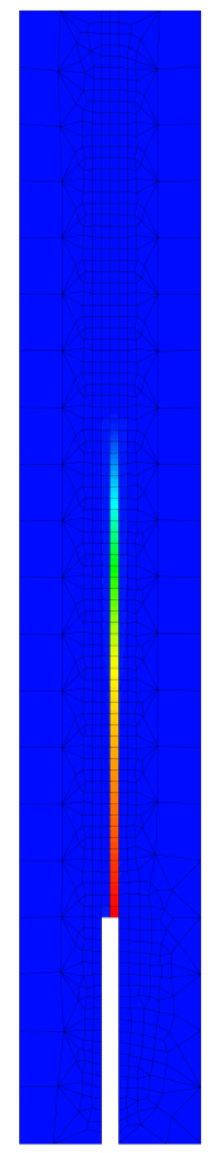

EPXX

$>-1.08 \mathrm{E}-08$

$<8.63 \mathrm{E}-06$

7. 33E-06

6. 92E-06

$6.51 E-06$

6.10E-06

$5.68 \mathrm{E}-06$

5. $27 \mathrm{E}-06$

$4.86 E-06$

4. $45 \mathrm{E}-06$

4. $04 \mathrm{E}-06$

$3.63 E-06$

3. $21 \mathrm{E}-06$

2. 80E-06

$2.39 \mathrm{E}-06$

1. $98 \mathrm{E}-06$

1. 57E-06

1. $16 \mathrm{E}-06$

7. $44 \mathrm{E}-07$

3. 32E-07

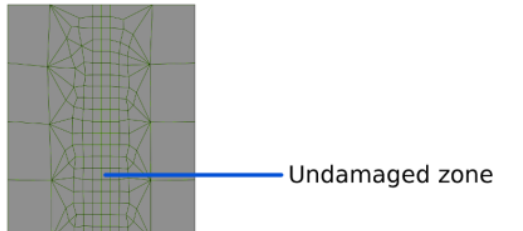

a)

b)

468

469 Figure 6. Initial numerical crack width (in meter) (a) and two-phase healing model (b)

470 


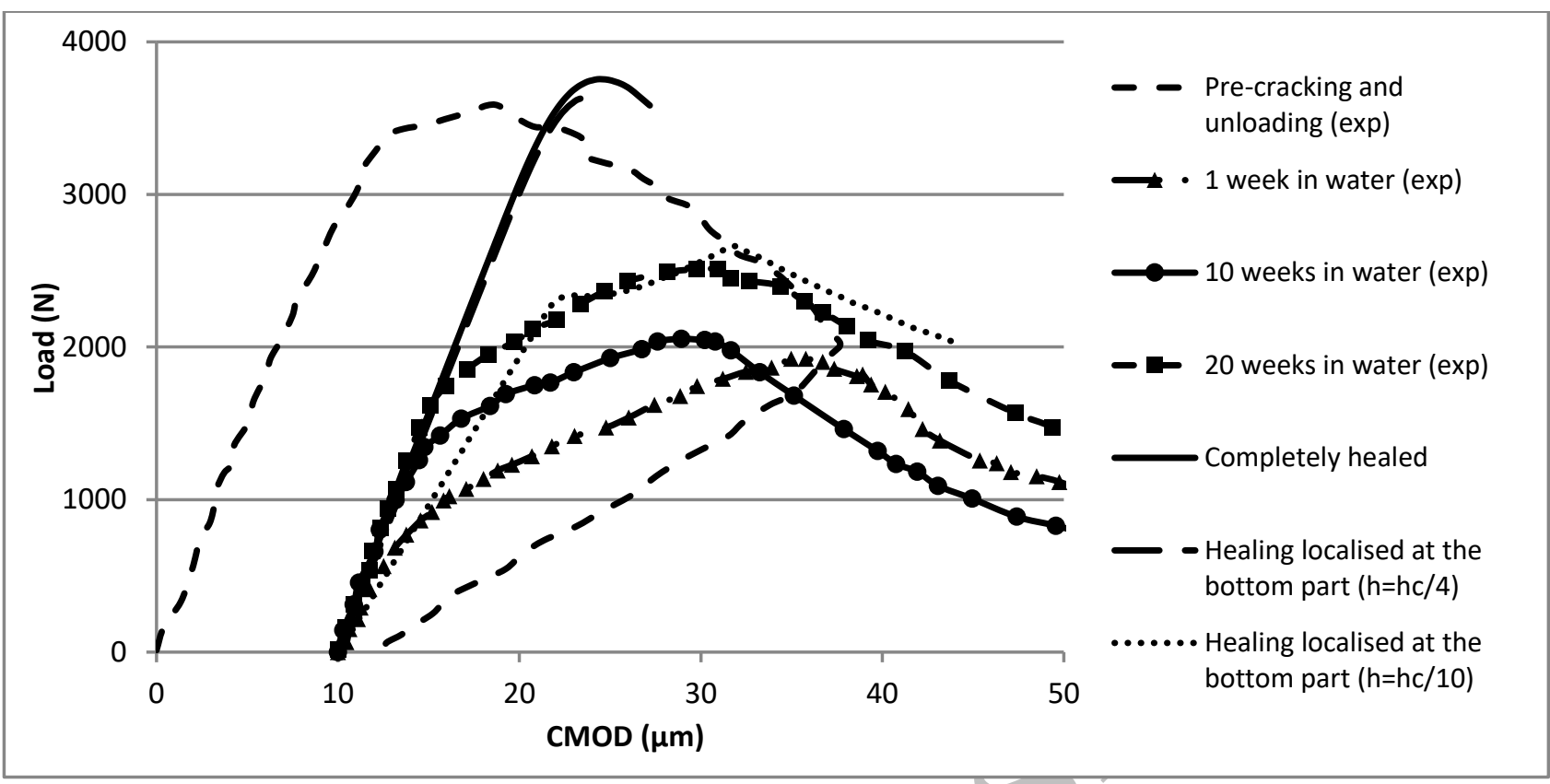

472 Figure 7. Influence of the extend of the healed zone during reloading on numerical curves

473 compared to experimental curves ( $\mathrm{h}$ is the height of the healed zone, hc the height of the

474 crack)

475

476

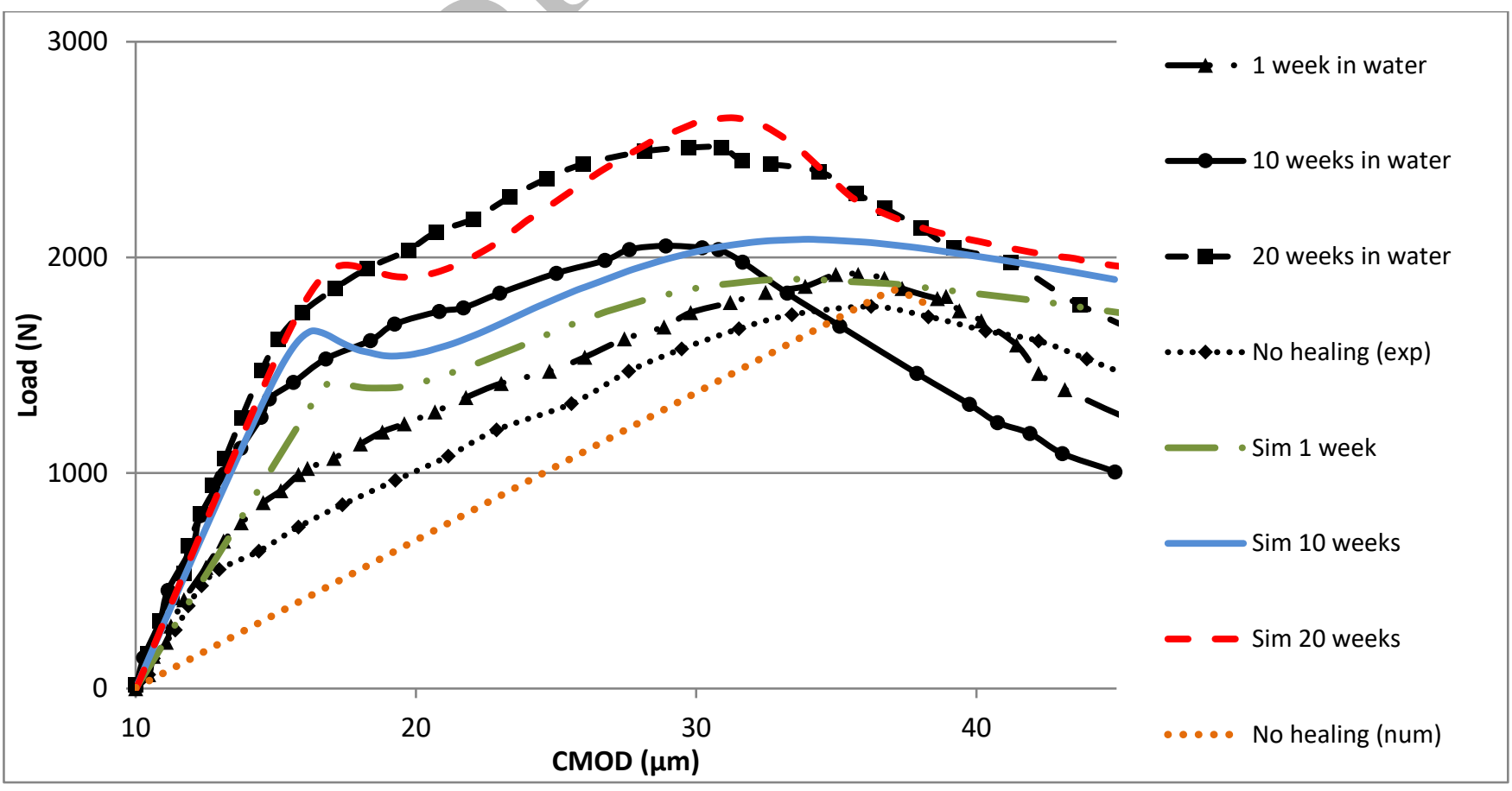

479 Figure 8. Experimental and numerical reloading curves for different healing periods 